\title{
Experimental and Numerical Investigation on Cold-formed Steel C Back-to-Back Beams
}

\author{
Kimcheng Kang $^{1 *}$, Taweep Chaisomphob ${ }^{2}$, Wasan Patwichaichote ${ }^{3}$, Eiki Yamaguchi ${ }^{4}$ \\ 1 Master student, Sirindhorn International Institute of Technology, Thammasat University, Thailand \\ 2 Associate Professor, Sirindhorn International Institute of Technology, Thammasat University, Thailand \\ 3 PhD student, Sirindhorn International Institute of Technology, Thammasat University, Thailand, and Assistant \\ Professor, Civil Engineering Department, Chulachomklao Royal Military Academy, Nakorn-Nayok, Thailand.
}

4 Professor, Department of Civil Engineering, Kyushu Institute of Technology, Kyushu, Japan

*Corresponding author: kangkimcheng1@yahoo.com

\begin{abstract}
Investigation on flexural behavior of cold-formed steel (CFS) C back-to-back beam has been conducted in this study. In North American Specification for the Design of Cold-Formed Steel Structural Members, there is only the information on the spacing condition of C back-to-back beam. In the present experiment, twelve C back-to-back beam specimens with different connection spacing and cross-sectional dimension were tested under four-point loading. Bolts were used for connecting two $C$ section beams. From the experimental result, the influence of the thickness and connection spacing of the $C$ back-to-back beams were observed. Nonlinear finite element analysis of the beam specimens are performed, and compared with experimental result. It was found that the difference in ultimate load obtained from experimental and numerical result, are less than 30 percent.
\end{abstract}

Keywords_C back-to-back beam, Cold-formed steel, Distortional Buckling, Finite Element Method.

\section{INTRODUCTION}

$\mathrm{V}$ arious shape of beam sections made of cold-formed steel (CFS) can be fabricated easily by using cold-roll forming machine. Cold-formed steels are applied in several members in the practical structures, such as: columns, beams, rafters, purlins, trusses. In the field of civil engineering (Fig. 1(a)), cold-formed steel members were used in factories, warehouses, roofs, car parks, etc. Moreover, CFS was also used as architectural decoration. The thickness of cold-formed steel is very thin compared to hot-rolled steel thickness. There are several types of cold-formed steel sections, but the popular sections are $\mathrm{C}$-section and Z-section. As shown in Fig. 1(b), C section, as mono-symmetric section, is easily failed by lateral torsional buckling according to the difference position of the shear center and the centroid of the cross section. In case that more resistance to lateral torsional buckling is required, built-up $\mathrm{C}$ backto-back (Fig. 1(c)) is introduced to improve its performance. In the specification [1], there is the guideline to calculate the maximum spacing for applying the cold-formed steel C back-to-back beam. Therefore, the experimental research on cold-formed steel built-up back-to-back beam is needed.

Liping Wang, et al. [2] studied about beam tests of cold-formed steel built-up sections with circle opening at the web. The objective of this study was to observe the flexural behavior, including the ultimate moment capacities and phenomena that cold-formed steel C backto-back members failed with circular web holes. Luis Laim, et al. [3] conducted 12 quasi-static four- point bending tests to obtain the ultimate loads and failure modes of the beams.

The structural behavior of built-up cold-formed steel beams that composed from $\mathrm{C}$ and $\mathrm{U}$ sections was presented, based on the experimental tests and numerical simulations.

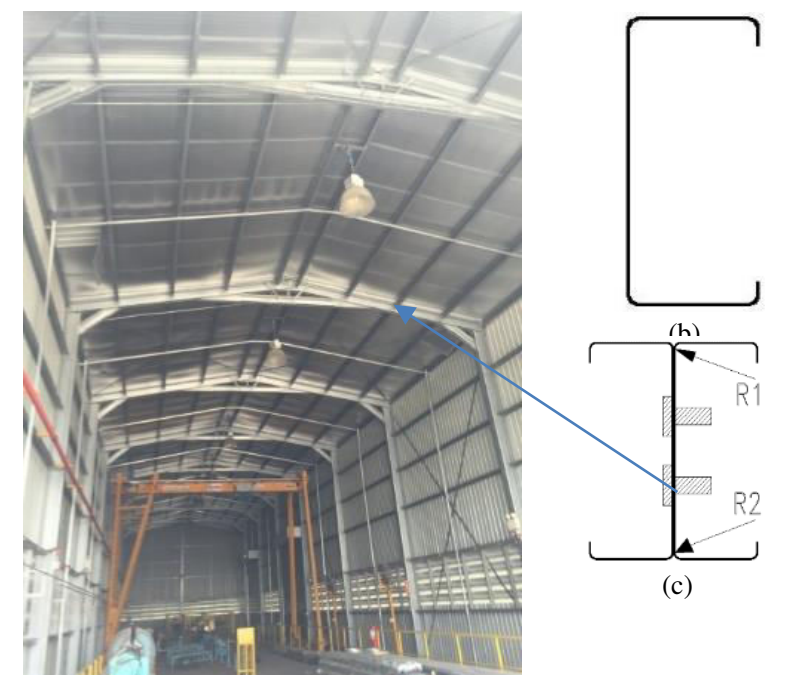

(a)

Fig. 1. (a). Application C back-to-back beam, (b). C section, (c) C back-to-back section

In this study, bolts were used for connecting both $\mathrm{C}$ section steel beams, and four-point loading was applied to the tested beams. The objective of the present test results was to examine on the ultimate loads and failure modes of the $\mathrm{C}$ back-to-back steel beams with three types cross-sectional dimensions and four values of connector spacing. 


\section{EXPERIMENTAL INVESTIGATION ${ }^{l}$}

\section{A. Type of Connection}

In this paper, bolt was kind of connections that was used in built-up beam. In one connection, there were one bolt at upper web and another bolt at lower web as Fig. 1(c). It was noted that when cold-formed steel back-to-back beam was used, the thickness of the web became double. Bolt joints were suitable and effective for applying into the cold-formed steel section with the condition that total thickness should be enough for installation with power actuated fasteners machine. For the bolts M12 (8.8) used in this study, the tensile stress was $800 \mathrm{MPa}$ and the diameter was $12 \mathrm{~mm}$.

\section{B. Material and specimen geometry}

12 specimens were tested with the overall beam length of 4 meters, and subjected to bending on the major $\mathrm{x}$-axis in order to observe the behavior of cold-formed steel $\mathrm{C}$ back-to-back beam. For the span length, it was $3.8 \mathrm{~m}$. The distance between $\mathrm{R} 1$ at corner top flange to the centre of the bolt is the same as the distance from the bolt to the bolt and from the bolt to $\mathrm{R} 2$ at corner bottom flange as shown in Fig. 1(c). The yield strength and ultimate strength vary with the thickness of the beam section. For the section with thickness $1.2 \mathrm{~mm}$, yield strength $\left(\mathrm{F}_{\mathrm{y}}\right)$ was $518 \mathrm{MPa}$ and ultimate strength $\left(\mathrm{F}_{\mathrm{u}}\right)$ was $599 \mathrm{MPa}$ and for the thickness $1.5 \mathrm{~mm}$, yield strength $\left(\mathrm{F}_{\mathrm{y}}\right)$ was $523 \mathrm{MPa}$ and ultimate strength $\left(\mathrm{F}_{\mathrm{u}}\right)$ was 610 $\mathrm{MPa}$. The cold-formed steel $\mathrm{C}$ back-to-back sections used in the present experiment were IC10012, IC10015 and IC15015 with the spacing L/2, L/3, L/4 and L/6, where L was the overall length of the beam. For the specimen IC10012L/2, it refers to cold-formed steel C back-to-back with the depth was $100 \mathrm{~mm}$, the thickness $1.2 \mathrm{~mm}$, and connector spacing L/2. Properties of $\mathrm{C}$ section were shown in Table 1.

Table 1. Properties of $\mathrm{C}$ section

\begin{tabular}{|c|c|c|c|c|c|}
\hline $\begin{array}{c}\text { Catalogue } \\
\text { Number }\end{array}$ & $\begin{array}{c}\mathrm{t} \\
\mathrm{mm}\end{array}$ & $\begin{array}{c}\mathrm{D} \\
\mathrm{mm}\end{array}$ & $\begin{array}{c}\mathrm{B} \\
\mathrm{mm}\end{array}$ & $\begin{array}{c}\mathrm{L} \\
\mathrm{mm}\end{array}$ & $\begin{array}{c}\text { Mass } \\
\text { unit length }(\mathrm{kg} / \mathrm{m})\end{array}$ \\
\hline $\mathrm{C} 10012$ & 1.2 & 102 & 51 & 12.5 & 2.1 \\
\hline $\mathrm{C} 10015$ & 1.5 & 102 & 51 & 13.5 & 2.62 \\
\hline $\mathrm{C} 15015$ & 1.5 & 152 & 64 & 15.5 & 3.59 \\
\hline
\end{tabular}

\section{Test set-up}

For the test set-up, both $\mathrm{C}$ sections with the overall $4 \mathrm{~m}$ length, were connected together at both webs by two bolts with the spacing equal to L/2, L/3, L/4 and L/6. At the section near support, one spacing of bolts was very small in order to make the support more stiffened and there were lateral supports in order to prevent the torque at the support sections as illustrated in Figure 2. The experimental installation of the back-to-back built-up C beams was illustrated in Fig. 3. The beam was loaded at two bearing plates $1.2 \mathrm{~m}$ from each support of the beam to create a pure bending moment in the middle without shear force. The four-point bending test set-up was shown in Fig. 3. The loading was applied by a hydraulic jack (no. 1 in Fig. 3) which was connected to hydraulic pump and was hung from steel frame (no. 10 in Fig. 3). To control the applied load during the test, a load cell of $50 \mathrm{kN}$ capacity was attached beneath the hydraulic jack and connected directly to the monitor (no. 2 in Fig. 3). In order to transfer the loading from hydraulic jack to the tested beam, I steel beam (no. 3 in Fig. 3) was used and applied at two points on the test beam. Moreover, the loading bearing plates (no. 4 in Fig. 3) was also put under the I steel beam in order to distribute the concentrated loading along the test beam. A spherical plain bearing was used to make a roller support condition to prevent the vertical displacement of the beams (no. 8 in Fig. 3) while other side of support was also fixed by clamp to prevent the horizontal displacement of the beams, namely pinned support (respectively no.11 and no. 9 in Fig. 3). The vertical displacement was measured using linear variable displacement transducer LVDTs of $10 \mathrm{~cm}$, maximum displacement capacity (no. 7) and the lateral displacement was measured using LVDT of $5 \mathrm{~cm}$, maximum displacement capacity (no. 12). Longitudinal strain gauges were attached on the top and bottom flange and the web (no. 6 in Fig. 3). All data measurement was recorded by using a data logger.

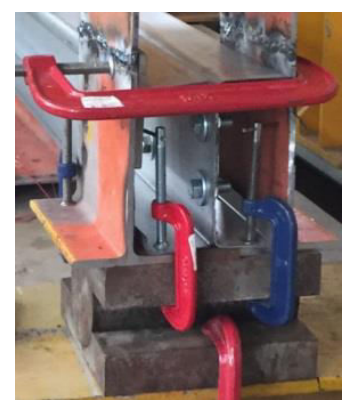

Fig. 2. Support set-up: Pinned support

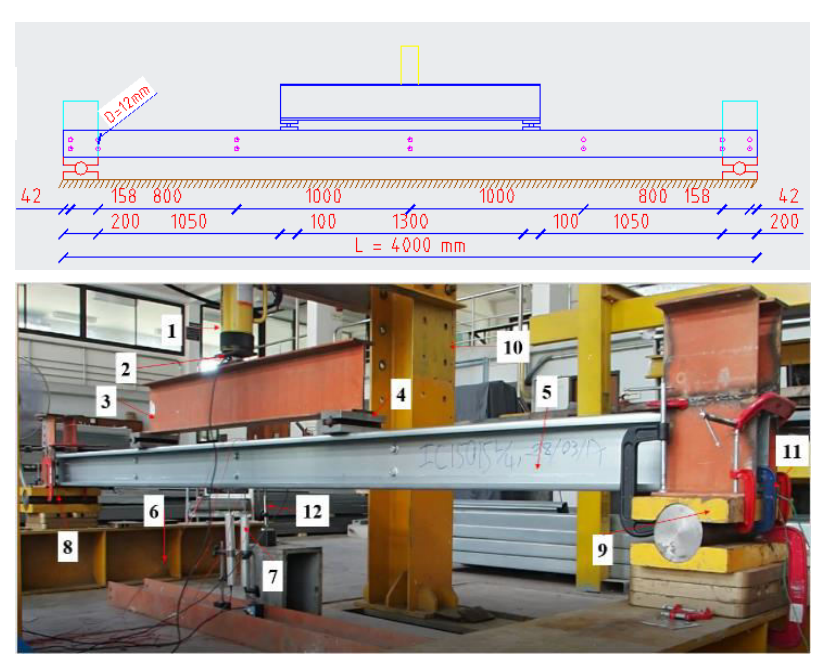

Fig. 3. Real set-up of cold-formed steel C back-to-back beam

\section{Test procedure}

Four-point bending tests were conducted to obtain the ultimate load capacity of the CFS beams. Steps of test procedure were described as follows: The two CFS C sections were assembled by bolt together to form the $\mathrm{C}$ back-to-back built-up beams. The four-point bending beam was measured vertical deflections and lateral 
defection at mid-span by LVDT. Four strain gauges for measurement longitudinal strain were attached at the mid-span section on the top flange and bottom flange. Then, the load was applied gradually under loading control by mean of hydraulic pump until the specimen failed where the lateral displacement or rotation or deflection was too large and load was immediately down. For each load steps, the displacements of the beams and strain gauges in the beams were recorded.

\section{E. Test result}

There were 12 tested specimens with different sections and spacings for observing maximum forces, maximum deflections and failure modes. All specimens were failed by Lateral Torsional Buckling (LTB) for section C-1 and Distortional Buckling (DB) for section C-2. Table 2 showed summary of the experimental result varying in thickness (t), height (h) and connection spacing (s).

Table 2. Summary of the experimental result varying with $\mathrm{t}, \mathrm{h}$ and $\mathrm{s}$

\begin{tabular}{|c|c|c|c|c|c||}
\hline \hline \multirow{2}{*}{ No } & \multirow{2}{*}{ Specimen name } & \multirow{2}{*}{ Max.Force(kN) } & \multirow{2}{*}{ Max Deflection $(\mathrm{mm})$} & \multicolumn{2}{|c|}{ Failure mode } \\
\cline { 5 - 6 } & & & & Section C-1 & Section C-2 \\
\hline 1 & IC10012L/2 & 8.89 & 47.78 & LTB & DB \\
\hline 2 & IC10012L/3 & 8 & 40.7 & LTB & DB \\
\hline 3 & IC10012L/4 & 8.1 & 41.01 & LTB & DB \\
\hline 4 & IC10012L/6 & 6.51 & 33.48 & LTB & DB \\
\hline 5 & IC10015L/2 & 9.16 & 38.26 & LTB & DB \\
\hline 6 & IC10015L/3 & 11.23 & 50.59 & LTB & DB \\
\hline 7 & IC10015L/4 & 9.6 & 40.26 & LTB & DB \\
\hline 8 & IC10015L/6 & 12.89 & 51.65 & LTB & DB \\
\hline \hline 9 & IC15015L/2 & 16.29 & 26.62 & LTB & DB \\
\hline 10 & IC15015L/3 & 18.25 & 31.21 & LTB & DB \\
\hline 11 & IC15015L/4 & 18.12 & 31.96 & LTB & DB \\
\hline 12 & IC15015L/6 & 16.76 & 28.58 & LTB & DB \\
\hline
\end{tabular}
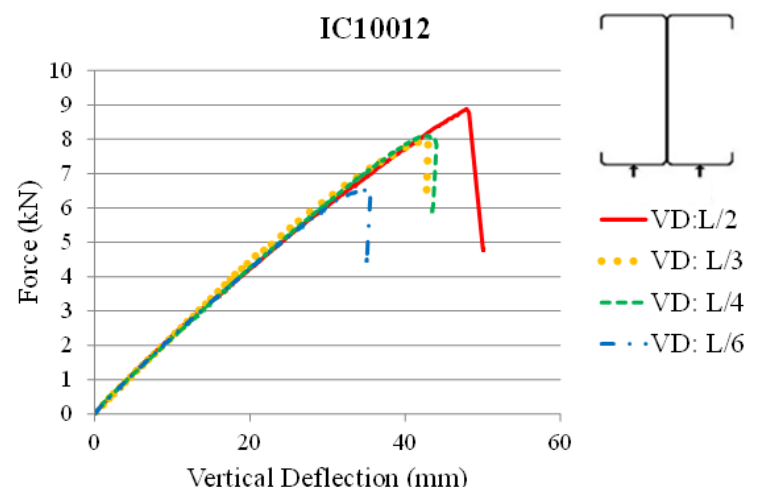

‥ VD: $\mathrm{L} / 3$ $---\mathrm{VD}: \mathrm{L} / 4$ $-\cdots \mathrm{VD}: \mathrm{L} / 6$

(a) Force-Vertical Deflection curve for IC10012

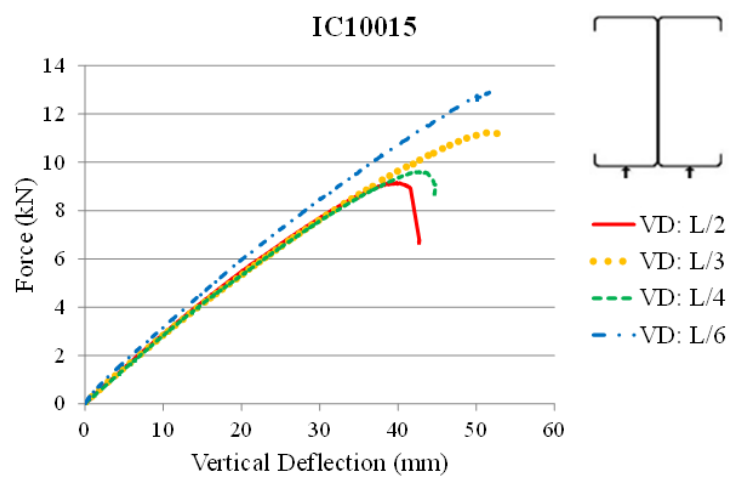

(b) Force-Vertical Deflection curve for IC10015
IC15015

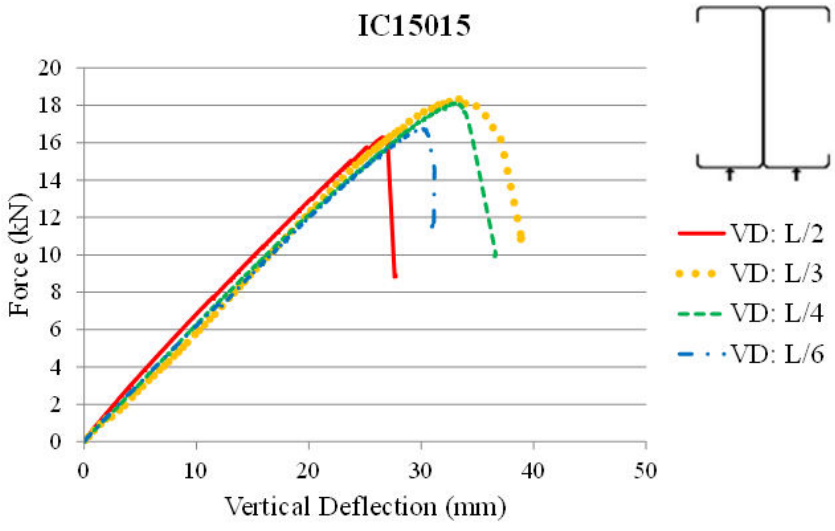

(c) Force-Vertical Deflection curve for IC15015

Fig. 4. Force-Vertical Deflection curves on various types of sections

From Table 2, the maximum force of IC10015L/2 and IC10015L/6 was $9.16 \mathrm{kN}$ and $12.89 \mathrm{kN}$ respectively. The increase of strength $40.72 \%$ was observed. The maximum force of IC10015L/3, IC $10015 \mathrm{~L} / 4$ and IC10015L/6 was over 1.23, 1.05 and 1.41 times higher than the one of $\mathrm{IC} 10015 \mathrm{~L} / 2$, respectively as shown in Figure 4. The maximum force of IC15015L/2,16.29 kN was less than that of IC15015L/6, $16.79 \mathrm{kN}$ around $2.89 \%$. The maximum force of IC15015L/3, IC15015L/4 and $\mathrm{IC} 15015 \mathrm{~L} / 6$ was over $1.12,1.11$ and 1.03 times higher than the one of $\mathrm{IC} 15015 \mathrm{~L} / 2$, respectively. In contrast, for the section IC10012, the maximum force of connector spacing $\mathrm{L} / 2,8.89 \mathrm{kN}$ is larger than the maximum force of the connector spacing $\mathrm{L} / 6,6.51 \mathrm{kN}$. The maximum force of IC $10012 \mathrm{~L} / 2$ was more than the maximum force of $\mathrm{IC} 10012$ with other connecter spacings. When the maximum force of large spacing is more than the one of small spacing, the reason might be due to the eccentricity of applied load on the beam, the material, the geometry imperfection and the force rate.

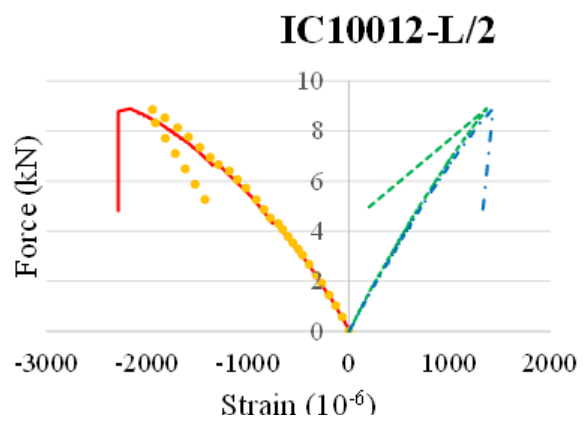

(a) Force-Strain Curve for IC10012L/2

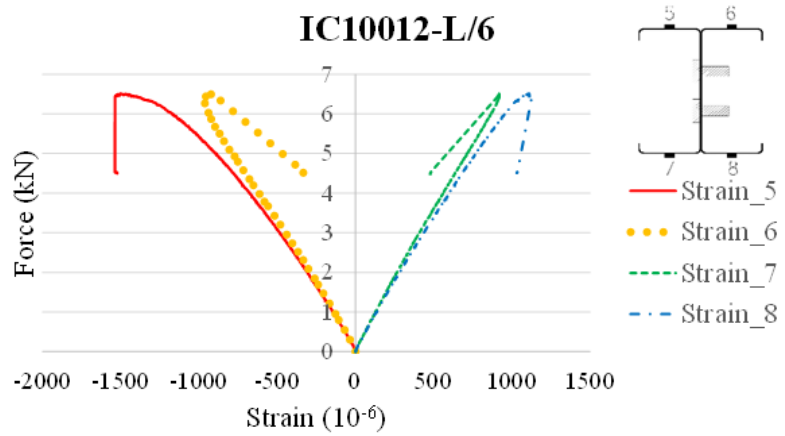

(b) Force-Strain Curve for IC10012L/6

IC10015-L/2

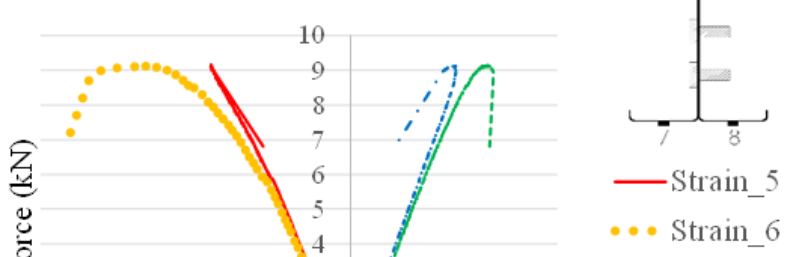


while strain_6 at top right flange was -1145.4 by observing the failure mode for top flange as distortional buckling. The strain between S_5 and S_6 was different around $38 \%$. The value of strain_7 and strain_8 were 1142.68 and 1171.06 respectively with slightly different around $2 \%$ due to the same level at the bottom of the flange.

\section{IC10012}

(c) Force-Strain Curve for IC10015L/2

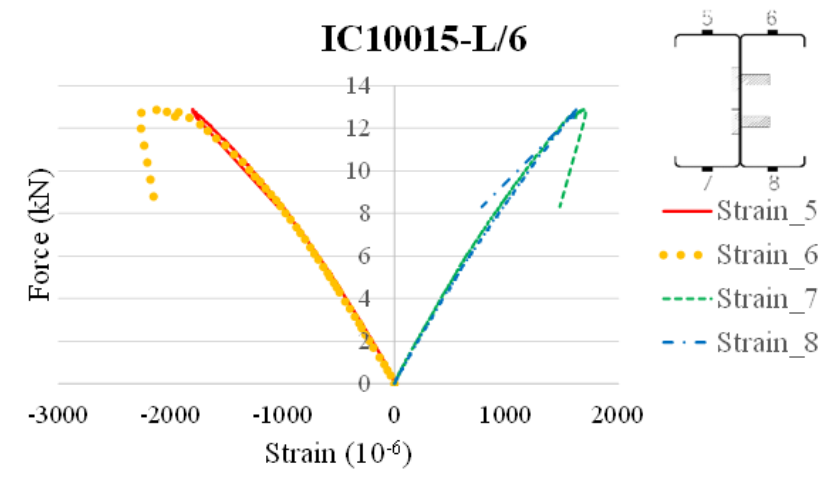

(d) Force-Strain Curve for IC10015L/6

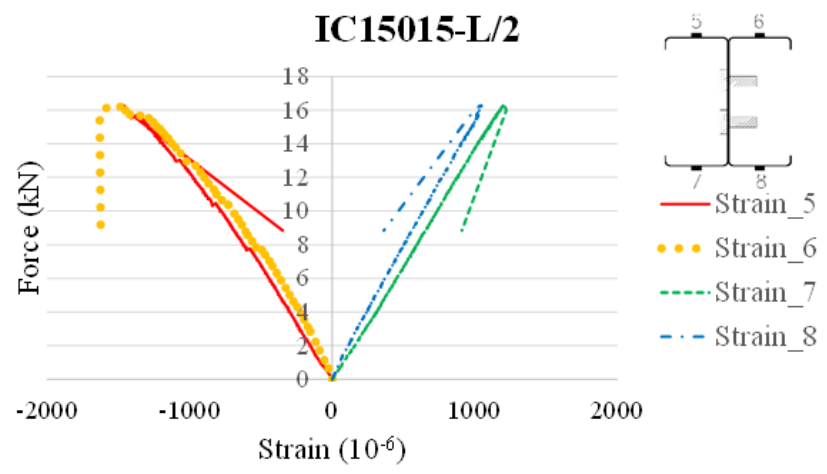

(e) Force-Strain Curve for IC15015L/2

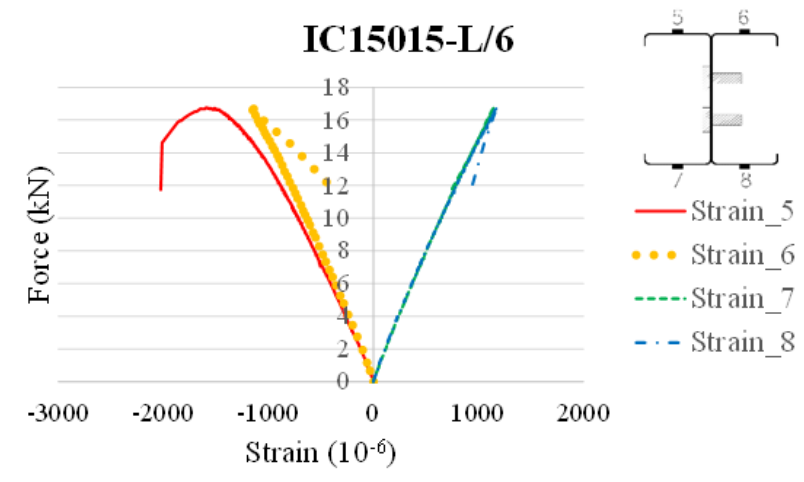

(f) Force-Strain Curve for IC15015L/6

Fig. 5. Force-Strain curve on various types of sections and spacings

Another parameter taken into account in this study was the strain of cold-formed steel section at mid-span as shown in Fig. 5. For IC15015L/6, strain_5 at the top left flange was -1582.91 and maximum load was $16.76 \mathrm{kN}$

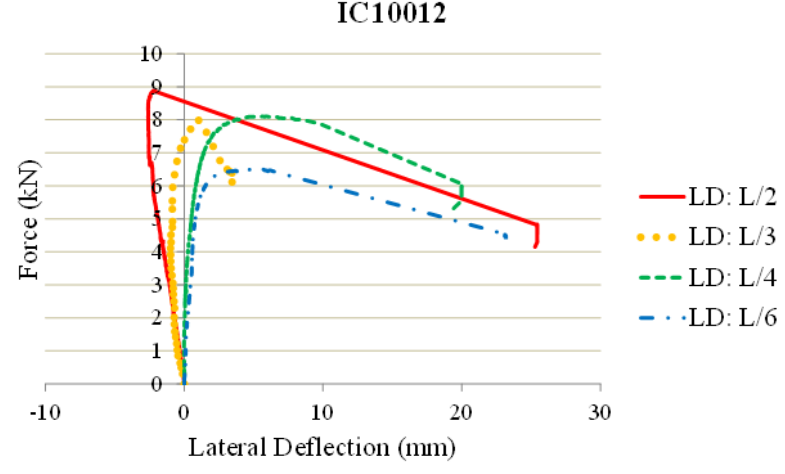

(a) Force-Lateral Deflection Curve for IC10012

IC10015

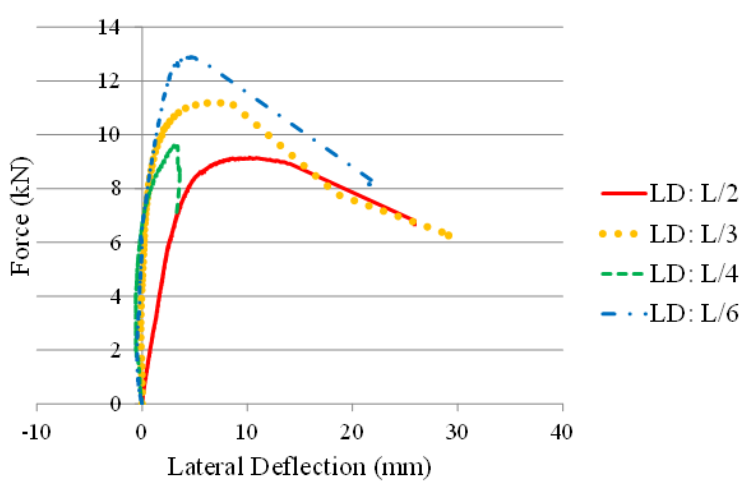

(b) Force-Lateral Deflection Curve for IC10015

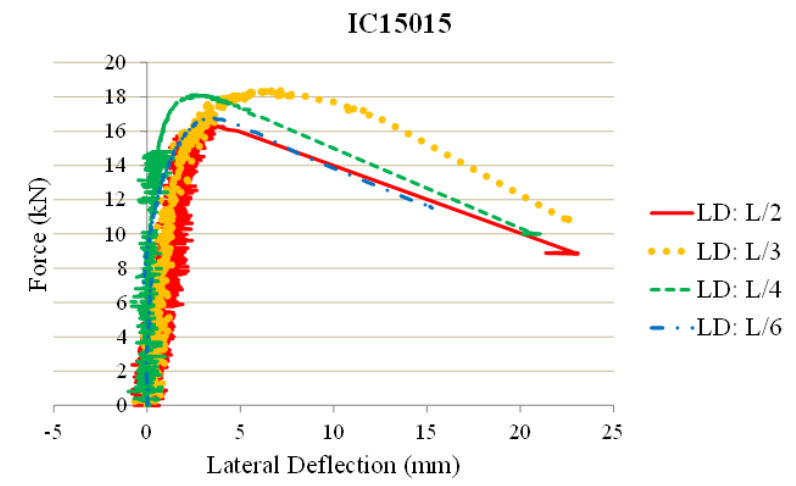

(c) Force-Lateral Deflection Curve for IC15015

Fig. 6. Force-Lateral Deflection curves on various types of sections

Through Figure 6, IC10012L/4, IC10015L/2, and IC15015L/3 had the maximum lateral deflection at the maximum force with the value of 5.69, 10.22, and 5.47 $\mathrm{mm}$, respectively among the same sections. All twelve beams had the failure of Lateral Distortional Buckling 
because the torque stiffness of $\mathrm{C}$ back-to-back section was weak compared to face-to-face section. Moreover, the maximum lateral deflection was not at the maximum force but it was at the unloading point.

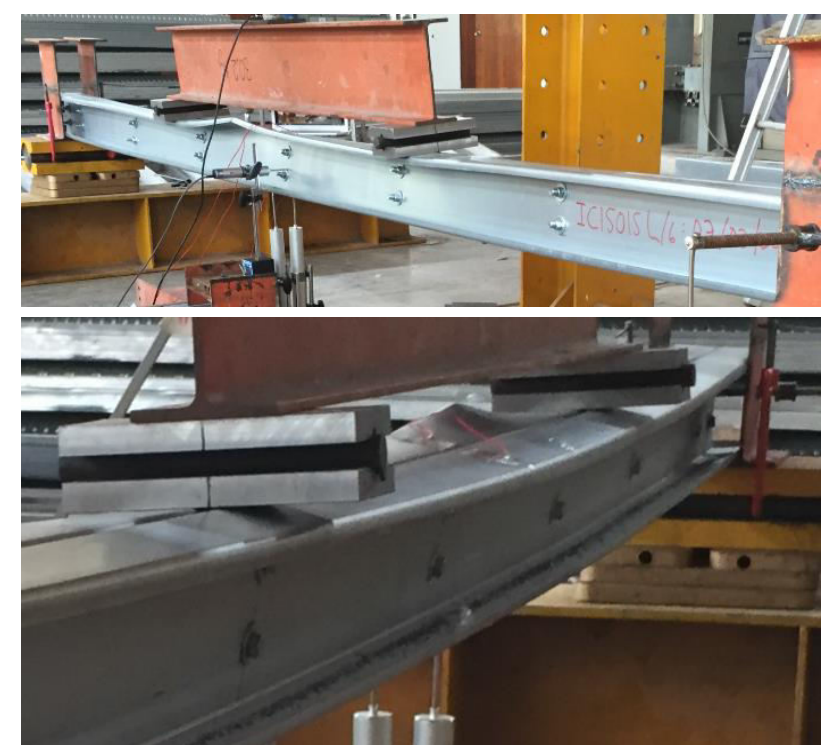

Fig. 7. Failure mode of IC15015L/6 (C-1: LTB; C-2: DB)
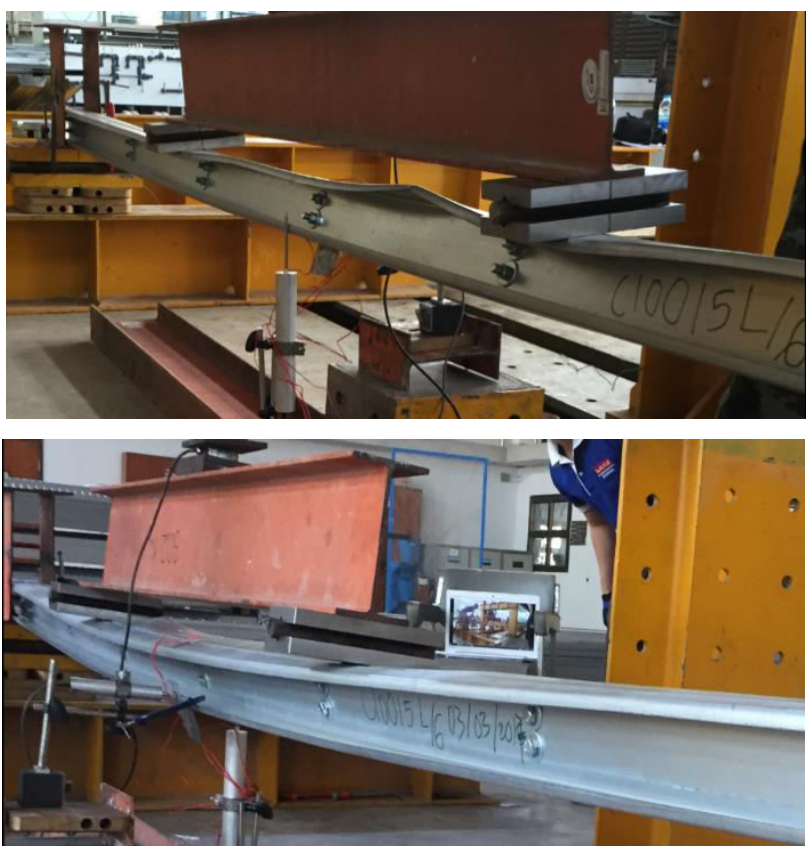

Fig. 8. Failure mode of IC10015L/6 (C-1: LTB; C-2: DB)
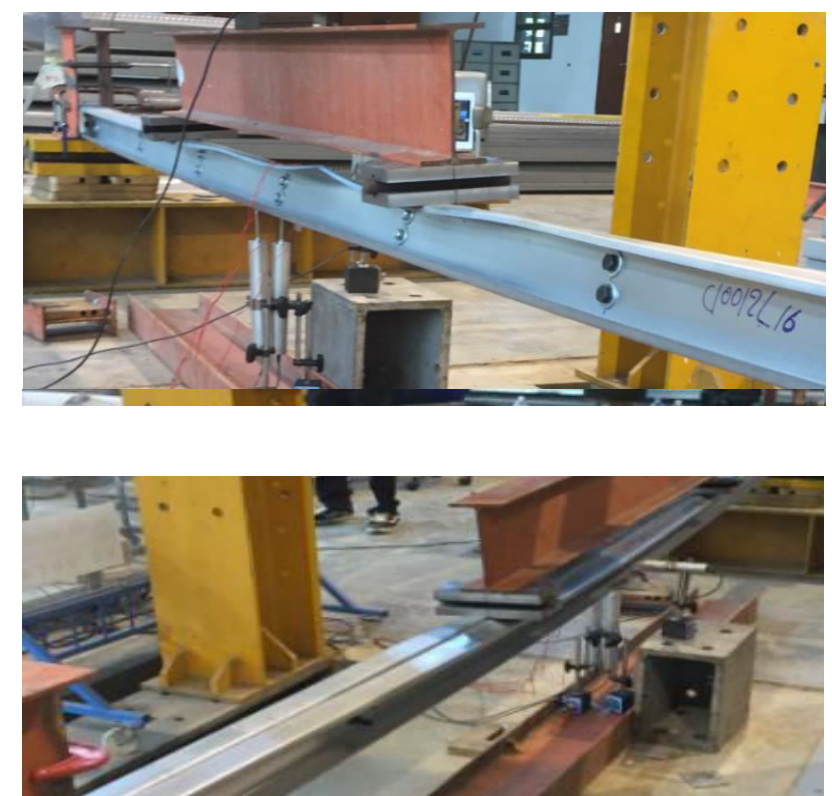

Fig. 9. Failure mode of IC10012L/6 (C-1: LTB; C-2: DB)

The failure mode can be observed that one section of IC10012L/6, IC10015L/6 and IC15015L/6 was failed by Distortional Buckling and another section was failed by Lateral Torsional Buckling as shown in Fig. 7, Fig. 8 and Fig. 9.

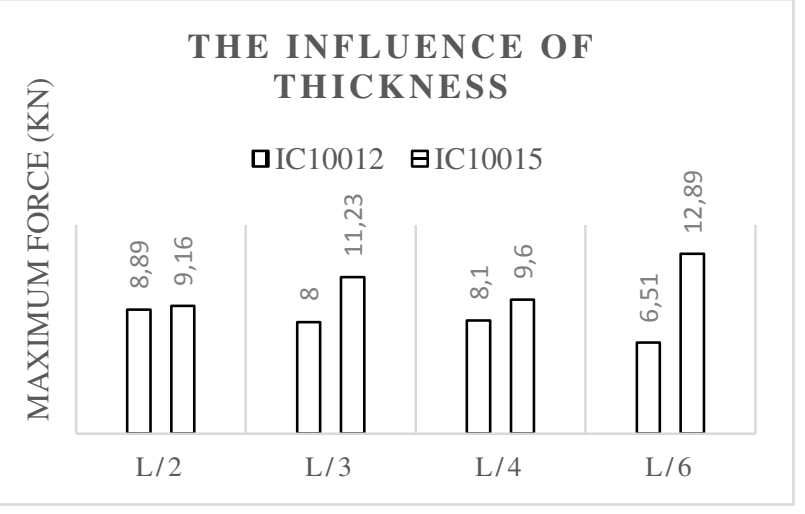

Fig. 10. The influence of thickness

When the thickness was increased so that the maximum force also increased. From IC10012L/2 to IC10015L/2, the thickness increased only $25 \%$, but the strength increased about $3 \%$ (Fig. 10). For spacing IC $100 \mathrm{~L} / 3$, the thickness increased from $1.2 \mathrm{~mm}$ to 1.5 $\mathrm{mm}$ so that the maximum force increased from $8 \mathrm{kN}$ to $11.23 \mathrm{kN}$ respectively, approximately $40 \%$. It was the same comparison for the spacing $\mathrm{L} / 4$, the maximum force increased around $19 \%$. In case the spacing $L / 6$, the maximum force increased about $98 \%$. For the big spacing, the max. force increased a little but for the small spacing, the max. force increased a lot.

\section{NUMERICAL SIMULATION}

In this research, ABAQUS program version 6.14-1 [4] was used to simulate CFS steel C back-to-back beams in order to verify the experimental test of the beams Fig. (11). The finite element program ABAQUS is a computational tool for modelling structures with material and geometric nonlinear behavior [Schafer and Moen 2010]. 12 beams were modelled to compared to the test. The force was applied at two points of loading bearing plate whose width was $10 \mathrm{~cm}$ and those loading bearing plates were installed symmetrically comparable to midspan. 


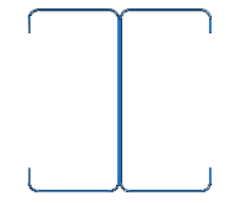

Fig. 11. Model of CFS C back-to-back beam IC10012L/4

\section{A. Modelling details and element type}

The element types that used in this program were shell elements and solid elements. For Cold-formed steel C back-to-back beam, the thickness dimension which ranges from $1.2 \mathrm{~mm}$ to $1.5 \mathrm{~mm}$, was very small compared to other two dimensions so that shell elements (S4R) were used. Solid elements (C3D8R) were used for loading bearing plates and support bearing plates because there is no very small dimension among three dimensions. S4R [4] stands for doubly-curved, a fournode (4), quadrilateral and stress/ displacement shell element $(\mathrm{S})$ with reduced integration $(\mathrm{R})$, a large-strain formulation, hourglass control and a first-order (linear) interpolation. Normally, when there is the reduced integration, so the computing time also decreases. Each node had 6 degrees of freedom which were three translations and three rotations. C3D8R element was a three-dimensional (3D), continuum (C), hexahedral and an eight-node brick element with reduced integration (R), hourglass control and first-order (linear) interpolation.

\section{B. Contact, loading and boundary conditions}

There were two types of contact which were used in this Finite Element Method (FEM) program. Surface-tosurface contact was the interaction between bottom surface of loading bearing plate and top flange surfaces of CFS C back-to-back beam (Fig. 12 (a)). Surface-tosurface contact was also applied between both webs of plain C-section. Moreover, two assumptions were introduced in this simulation for the contact properties. First assumption, frictionless was selected for tangential behavior. Second assumption, hard contact was chosen for normal behavior. For tie contact, it was applied between the bottom surfaces of both $\mathrm{C}$ sections and the top surface of the support (Fig. 12(b)). For the function of tie contact, both surfaces were touched together. When the beam failed, there is no gap between both surfaces.

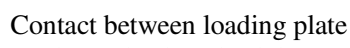

Contact between both webs of plain C-section

(a) Surface-to-surface contact

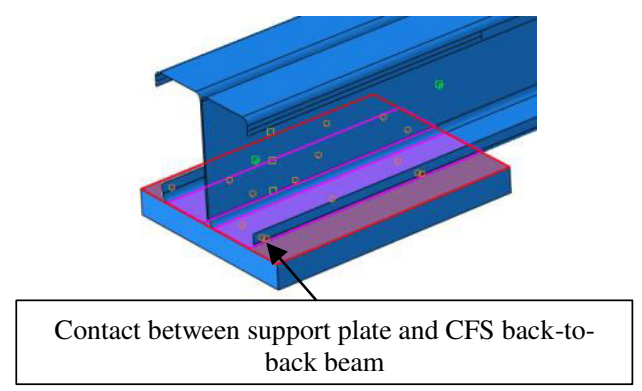

(b) Tie contact

Fig. 12. Type of contact conditions: (a) and (b)

In opposite, for surface to surface contact, both surfaces were touched together, but when the beam failed, some part of the surface was touched and some part of the surface was not touched.

In the real experimental test, the beam supports and the loading were applied on rigid plates attached to the beam in order to distribute the concentrated forces on them. In order to load the beam, the controlled displacement was imposed vertically with Y direction on the bearing plate. To model the beam in the program as experimental test, $\mathrm{X}$ and $\mathrm{Z}$ direction were restrained at both loading bearing plates so that there were no lateral and longitudinal movement of the loading bearing plates as illustrated in Fig. 13. The support bearing plates and the loading bearing plates were rigid. For roller support, all translations of one line nodes in Y direction located at the middle bottom surface were constrained while the translation of one node in $\mathrm{X}$ direction was constrained. In particular, lateral support reactions in $\mathrm{X}$ direction of one line at both top lips were also constrained to prevent the twist at the support (Fig. 14 (a)). For pinned support, all translations of one line nodes in $\mathrm{Y}$ and $\mathrm{Z}$ direction were constrained at the same position as roller support and other constraints were the same condition as roller support (Fig. 14 (b)).

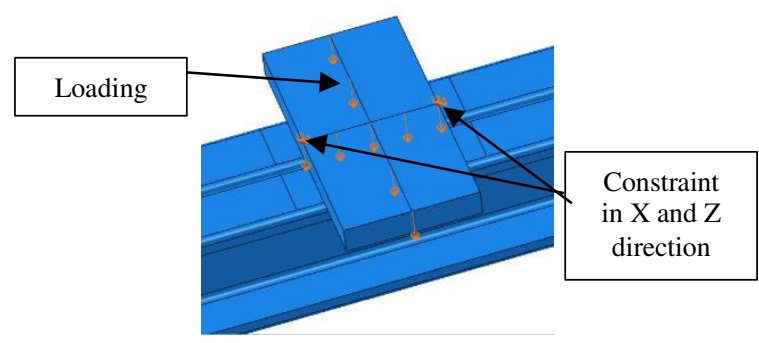

Fig. 13. Constraints of loading bearing plate
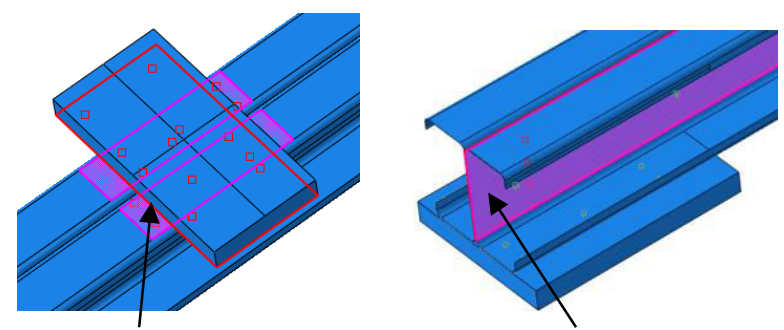

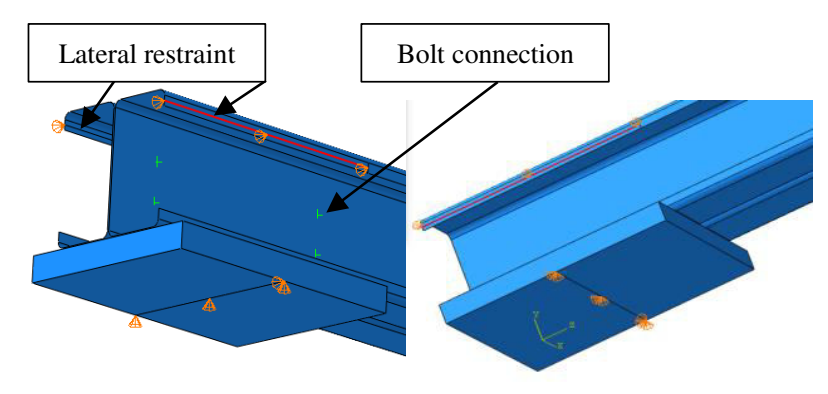




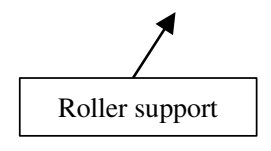

(a) Roller and lateral support

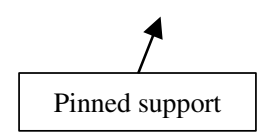

(b) Pinned and lateral support
Fig. 14. Support simulation: (a) and (b)

\section{Material modelling}

Material nonlinearity in the cold-formed steel beams was modelled with von Mises yield criteria and isotropic hardening. Material for the thickness $1.2 \mathrm{~mm}$ and 1.5 $\mathrm{mm}$ was got from the coupon test. CFS C back-to-back beam was plastic which divided into two zones. In elastic zone, Young's modulus $(\mathrm{E})=208 \mathrm{GPa}$ and Poisson's ratio $(\vartheta)=0.3$. In plastic zone, yield stress and plastic strain were significantly inputted. A loading and support bearing plate were modelled as a rigid solid element which was 1000 times of Young's modulus.

\section{Finite element mesh and connection}

Finite element mesh of CFS C back-to-back beam was $7.5 \mathrm{~mm}$ (Fig. 15). This size is small enough to run the program. At the section corner, three segments were divided to get good result and the lip was divided into two segments. For loading bearing plates and support bearing plates, the finite element sizes were $10 \mathrm{~mm}$ and $20 \mathrm{~mm}$ respectively.

Through the observation in the experimental test, there was no failure with the bolts so that simplified bolts, fasteners function in Abaqus program were to connect two plain C-sections by constraining all rotational and translational degrees of freedom of the nodes at the bolt location. Therefore, the radius of bolt was $6 \mathrm{~mm}$.

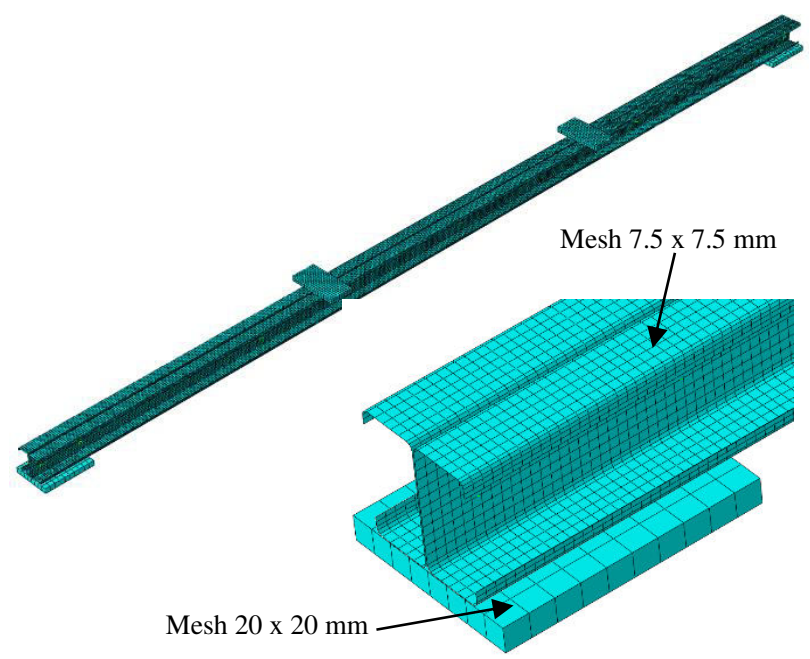

Fig. 15. Mesh of the CFS beam, loading plate and support plate

\section{E. Analysis}

For analysis, the nonlinear geometric parameter $($ NLGEOM $=$ ON) was set to control the inclusion of nonlinear effects of large displacements and affect subsequent steps.

\section{F. Comparison between numerical and test results}

1) Maximum force-vertical deflection comparison

The maximum force, failure mode and ratio of CFS C back-to-back beam were compared between the numerical simulation and experimental test as summarized in Table 3. From Table 3, it was observed that the ratio between FEM and the test was from 0.82 to 1.36 .

Table 3. Comparison between test and FEM result

\begin{tabular}{|c|c|c|c|c|c|c|c|c|}
\hline \multirow{3}{*}{ No } & \multirow{3}{*}{ Specimen } & \multicolumn{3}{|c|}{ Experimental results } & \multicolumn{3}{|c|}{ FEM result } & \multirow{3}{*}{$\begin{array}{l}F_{F E M} \\
F_{\text {test }}\end{array}$} \\
\hline & & \multirow{2}{*}{$\begin{array}{l}\mathrm{F}_{\text {test }} \\
(\mathrm{kN})\end{array}$} & \multicolumn{2}{|c|}{ Failure mode } & \multirow{2}{*}{$\begin{array}{l}\mathrm{F}_{\mathrm{FEM}} \\
(\mathrm{kN})\end{array}$} & \multicolumn{2}{|c|}{ Failure mode } & \\
\hline & & & $\mathrm{C}-1$ & $\mathrm{C}-2$ & & $\mathrm{C}-1$ & $\mathrm{C}-2$ & \\
\hline 1 & IC10012L/2 & 8.89 & LTB & DB & 7.32 & LTB & DB & 0.82 \\
\hline 2 & IC $10012 \mathrm{~L} / 3$ & 8 & LTB & DB & 7.88 & LTB & DB & 0.99 \\
\hline 3 & IC10012L/4 & 8.1 & LTB & DB & 7.72 & LTB & DB & 0.95 \\
\hline 4 & IC10012L/6 & 6.51 & LTB & DB & 7.88 & LTB & DB & 1.21 \\
\hline 5 & IC10015L/2 & 9.16 & LTB & DB & 11 & LTB & DB & 1.20 \\
\hline 6 & IC10015L/3 & 11.23 & LTB & DB & 11.2 & LTB & DB & 1.00 \\
\hline 7 & IC10015L/4 & 9.6 & LTB & DB & 12.2 & LTB & DB & 1.27 \\
\hline 8 & IC10015L/6 & 12.89 & LTB & DB & 12.1 & LTB & DB & 0.94 \\
\hline 9 & IC15015L/2 & 16.29 & LTB & DB & 21.5 & LTB & DB & 1.32 \\
\hline 10 & IC $15015 \mathrm{~L} / 3$ & 18.25 & LTB & DB & 18.4 & LTB & DB & 1.01 \\
\hline 11 & IC $15015 \mathrm{~L} / 4$ & 18.12 & LTB & DB & 20.1 & LTB & DB & 1.11 \\
\hline 12 & IC $15015 \mathrm{~L} / 6$ & 16.76 & LTB & DB & 22.8 & LTB & DB & 1.36 \\
\hline
\end{tabular}

*Note: C-1: one $\mathrm{C}$ section side; $\mathrm{C}-2$ : the other $\mathrm{C}$ section side; LTB: Lateral Torsional Buckling; DB: Distortional Buckling.

The max. force-vertical deflection graphs between FEM and test at mid-span for IC10012L/2, IC10012L/6, IC10015L/2, IC10015L/6, IC15015L/2 and IC15015L/6 were illustrated and compared in Figure 16.

\section{IC10015-L/2}

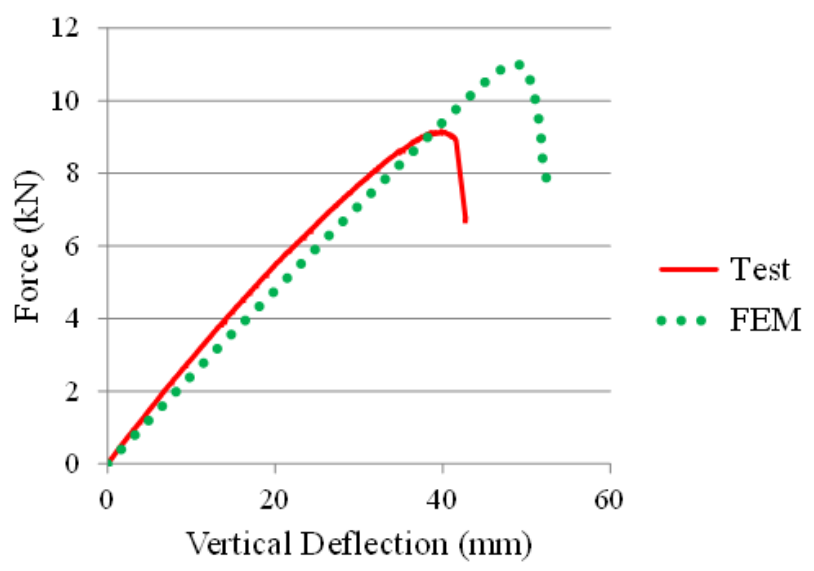

(a). Force-Vertical Deflection Graph of IC10015L/2

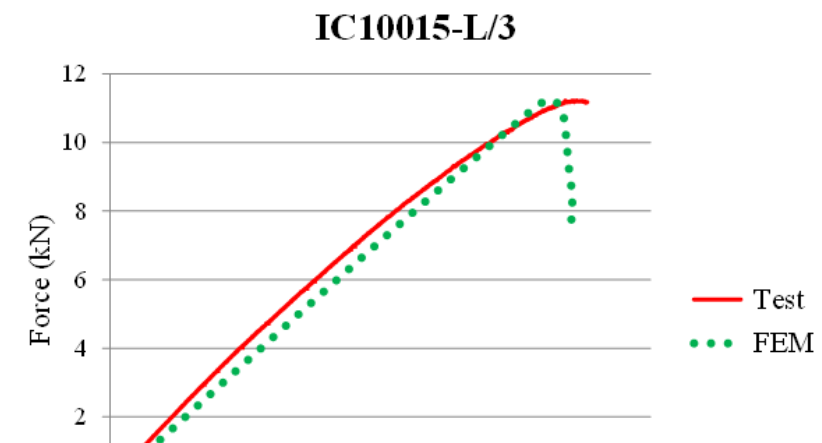


(b). Force-Vertical Deflection Graph of IC10015L/3

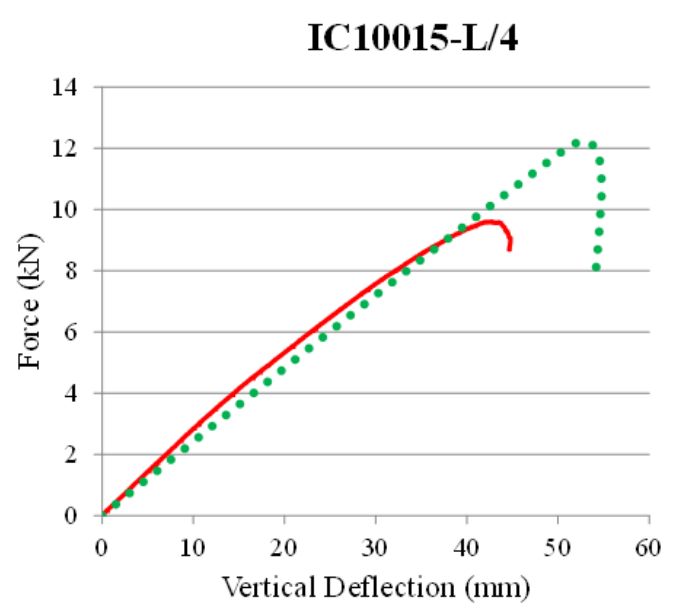

(c). Force-Vertical Deflection Graph of IC10015L/4

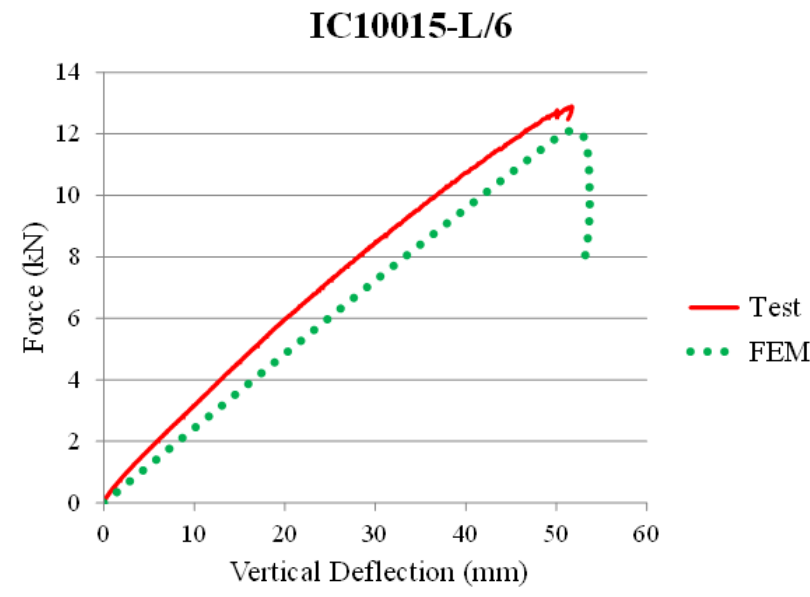

(d). Force-Vertical Deflection Graph of IC10015L/6

Fig. 16. Comparison graphs of Test and FEM Force-Vertical Deflection

\section{2) Failure modes}

According the table 3, the failure modes of all twelve Cold-formed steel $\mathrm{C}$ back-to-back beams were Lateral Torsional Buckling for section $\mathrm{C}-1$ and Distortional Buckling for section C-2. All failure modes of 12 beams obtained from FEM had in good agreement with the experimental test. The detail of failure modes between FEM and the test was shown in Table 3. The failure modes of IC10015L/4 and IC10015L/2 in Abaqus program were compared with the experimental test in the laboratory (Fig. 17 and 18).

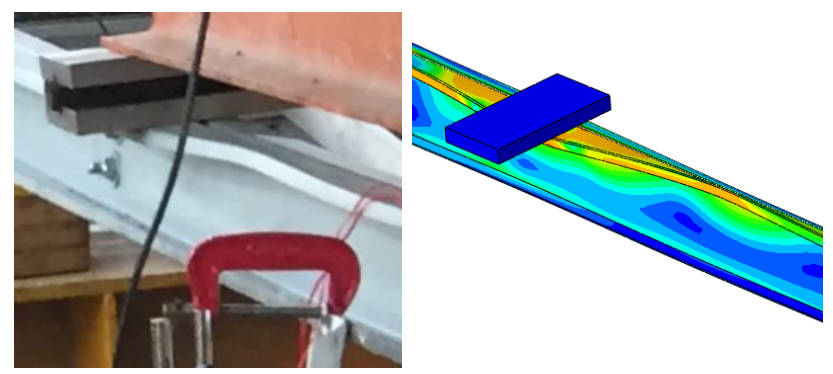

(a). Failure mode near the loading plate

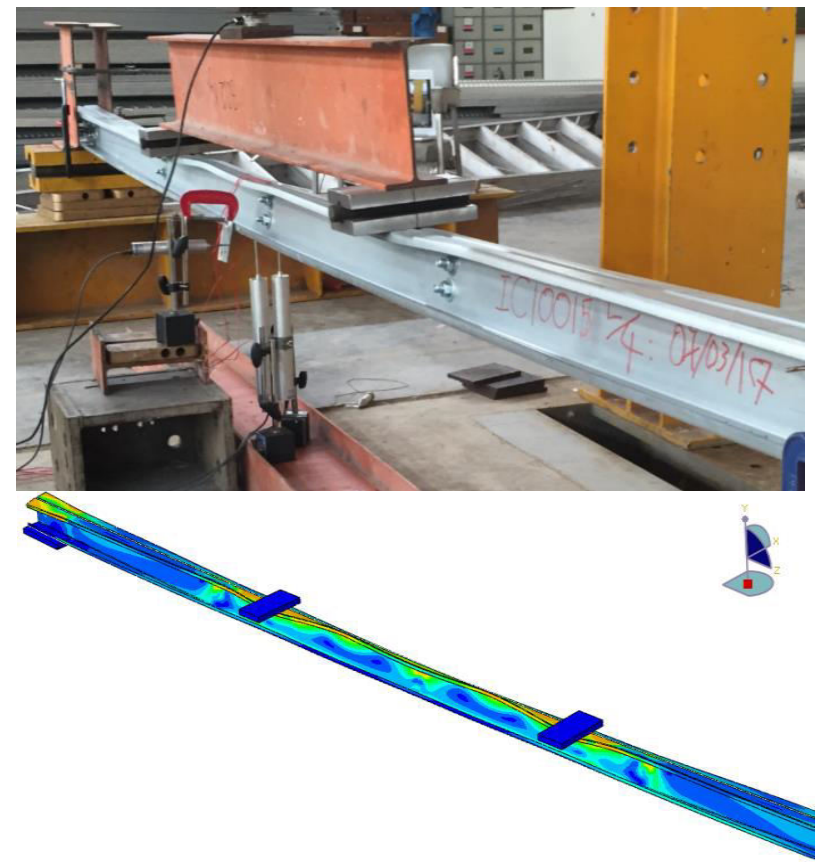

(b). Distortional Buckling of IC10015L/4

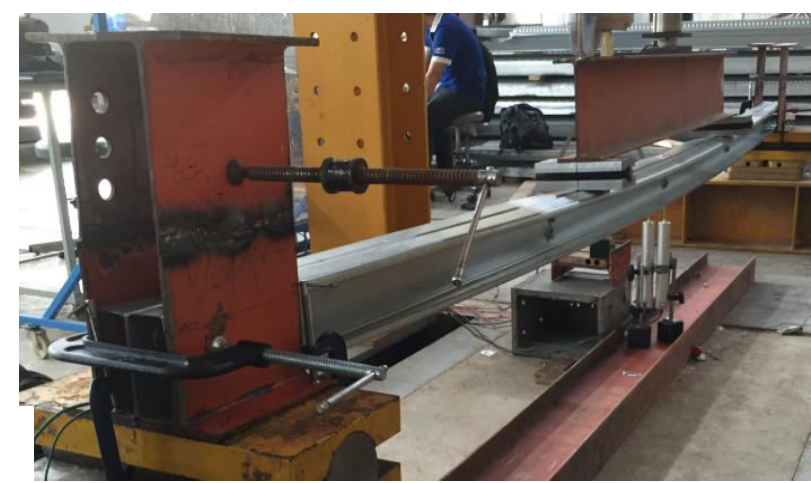

S, Mises

SNEG, (fraction $=-1.0$ )

(Avg: $75 \%$ )

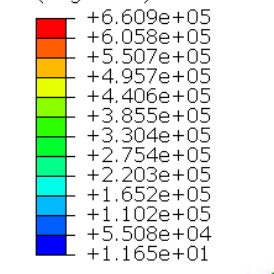


(c). Lateral Torsional Buckling of IC10015L/4

Fig. 17. Failure mode of IC10015L/4 between Test and FEM
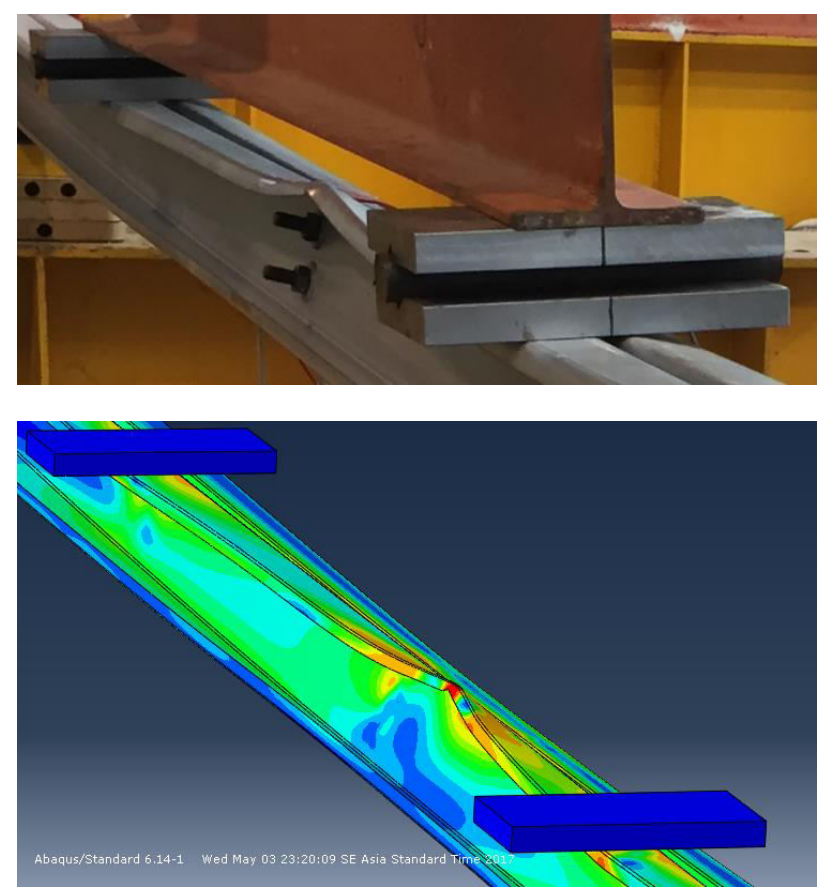

Fig. 18. Failure of IC10015L/2 between FEM and Test

\section{CONCLUSIONS}

Twelve specimens of cold-formed steel C back-to-back beams were tested under four-point loading, to investigate their flexural behavior. For failure modes, all specimens were failed by Lateral Torsional Buckling (LTB) for section C-1 and Distortional Buckling (DB) for section C-2. After observation, increase the thickness $25 \%$ increased the maximum force from $3 \%$ to $98 \%$. The influence of thickness with the connection spacing L/2, the maximum force increased $3 \%$ but for connection spacing $\mathrm{L} / 6$, the maximum force increased $98 \%$. In terms of the influence of connector spacing, the maximum forces of $\mathrm{L} / 6, \mathrm{~L} / 4, \mathrm{~L} / 3$ are larger than the maximum forces of $\mathrm{L} / 2$ from $3 \%$ to $41 \%$ except IC10012 that the maximum force of $\mathrm{L} / 6$ is smaller than that of $\mathrm{L} / 2$. Finite element analysis considering geometric and material nonlinearity was performed by using ABAQUS program. The failure modes of CFS $C$ back-to-back beams from numerical simulation comparatively agreed with the modes observed in the experiment. The ratio between the experimental test and numerical simulation was from 0.82 to 1.36 in term of maximum forces.

Further research is recommended to study about the effect of span length, the influence of height that are the significant parameters.

\section{ACKNOWLEDGEMENTS}

The authors are very grateful to Bluescope Lysaght Thailand Limited that sponsored $\mathrm{C}$ section steel specimens for this important research. This research is supported by AUN/SEED-Net. The authors also thanks to Mr. Wasan Patwichaichote that gave the place for doing the experiment in Civil Engineering laboratory at Chulachomklao Royal Military Academy (CRMA).

\section{REFERENCES}

[1] AISI, North American Specification for the Design of ColdFormed Steel Structural Members, S100-12, ed., 2012.

[2] Liping Wang, Ben Young: 'Beam tests of cold-formed steel built-up sections with web perforations'. Journal of construction Steel Research 115, pp. 18-33, 2015.

[3] Luis Laim, Joao Paulo C Rodrigues, and Luis Simoes da Silva: 'Experimental and numerical analysis on the structural behaviour of cold-formed steel beams'. Thin-Walled structure 72, pp. 1-13, 2013.

[4] Simulia. Abaqus/CAE. Version 6.14-1. 